\title{
Co-morbidity: the hydra of contemporary
}

\section{psychiatry?}

\author{
Thomas J Fahy
}

Ir J Psych Med 1997; 14(1): 3

Recent years have seen much discussion of multiple psychiatric diagnoses within individual patients, thrown up by large scale community surveys of psychiatric disorder using either DSM or ICD systems of classification. ${ }^{1.2} \mathrm{At}$ first sight it would appear that different Axis I psychiatric disorders, particularly depressive and anxiety disorders, cluster together in individuals' lifetimes to an extent far greater than would be expected by chance. This clustering is most marked within what used to be called the common neurotic disorders.

The consistency of this finding, in treated and untreated populations has refuelled old debates centred on an artificial division between general vulnerability to neurosis versus categorical clinical entities deserving of separate study. ${ }^{3}$ Midway between is a 'dimensional' view, a kind of statistical mutant position, the clinical application of which would require all psychiatrists to carry personal computers if only to retrieve their fees from insurance companies.

Debates about classification in psychiatry are of course nothing new and will continue until aetiological knowledge becomes sufficient to base taxonomy on something more than provisional syndromal subtypes - regimented as in a stamp album as if they were all of equal importance and quite unrelated one to another. Meantime, widely diverse epidemiological estimates of co-morbidity are likely to be reported, depending on whether 'caseness' is decided parsimoniously by traditional clinical methods or liberally by standard diagnostic schedules.

Andrews and his Australian group have brought together data from epidemiologic, genetic and treatment studies of neurotic disorders which point once more to a common vulnerability factor reminiscent of Eysenck's neuroticism (the general neurotic syndrome) underlying most if not all of the (mild) depressive and anxiety disorders set out separately in both DSM-IV and ICD-10. In a refreshing return to clinical common sense, Andrews leavens his conclusions with a disarmingly simple question: why, if so many disorders succeed each other in a patient's lifetime, do patients themselves persist in the belief that they have but one primary disorder and that this makes them vulnerable to others in the face of stress?

Other commentators, too, see a need to distinguish between primary and secondary, co-occurring and sequential co-morbid disorders. These suggestions may pacify experienced clinicians who lament the substitution of pencil and paper diagnosis for good clinical judgement. Thus, co-morbidity amongst the common neuroses is being brought to heel by the appreciation that certain

Thomas J Fahy, MD, FRCPsych, FRCPI, DPM, Professor, Department of Psychiatry, Clinical Science Institute, University College Galway, Co Galway, Ireland. SUBMITTED: DECEMBER 6, 1996 disorders which are unusually clear cut such as panic disorder and obsessional compulsive disorder, are not casually to be equated with general anxiety disorder, dysthymia and adjustment disorders which are in their turn more vague, more closely related to personality and, significantly, more susceptible to genetic than to environmental influences.

Flowing from these apparently esoteric issues, political and social debates with psychiatry at centre stage have already begun. Latter day Szasz type commentators predict that reckless labelling of ordinary citizens with DSM disorders will threaten the very fabric of society, as reflected in reportedly huge world wide sales of Prozac. Much of the credit for overdue recognition of the public health importance of psychiatric disorder must of course go to the successful promotion of DSM in the United States and ICD in Europe.

A predictable backlash, however, is already in motion, aimed at the 'medicalisation' of personality disorders and consequent decline in the currency of personal responsibility. It follows that diagnostic systems such as DSM and ICD which encourage multiple diagnosis are two edged swords whose use must be tempered by careful clinical observations even though the latter present quite formidable problems of method. This middle road is necessary so that research is not guided merely by pocket summaries and there is no return to the heuristically sterile fog of Meyerian common sense psychiatry, which eschews classification altogether.

These are not mere trivial academic asides. Clarity of thought and purpose are essential if the notorious association between somatic and psychiatric morbidity is ever to be understood in fields such as cardiology, oncology and endocrinology. But the enthusiasm of psychiatry for the success of its own propaganda must be restrained: otherwise the gains painfully won in the last decade for the recognition of the plight of patients may be sacrificed by excessive demands on communities unable or unwilling to respond. These are issues of importance not only to researchers, to politicians and sociologists but to all who would attempt to teach psychiatry. Taxonomy, until lately a neglected subject has again come of age and it behoves all psychiatrists to ensure that the baby of good clinical judgement is not thrown out with the bath water of taxonomic nihilism.

References

1. Robins LN, Regier DA eds. Psychiatric disorders in America the epidemiologic catchment area study. New York: Free Press, 1991.

2.Kessler RC, Zhao S et al. Lifetime and 12 month prevalence of DSM-III-R psychiatric disorders in the United States. Arch Gen Psychiatry 1994; 51: 8-19. 3. Goldberg D. A dimensional model for common mental disorders. Br J Psychiatry 1996; 168 (30): 44-9.

4. Andrews G. Comorbidity and the general neurotic syndrome. $\mathrm{Br} J$ Psychiatry $1996 ; 168(30): 76-84$ 